\title{
The investigation of factors related to suicide attempts in Southeastern Turkey
}

\author{
This article was published in the following Dove Press journal: \\ Neuropsychiatric Disease and Treatment \\ 23 February 2016 \\ Number of times this article has been viewed
}

\section{Aslihan Okan Ibiloglu \\ Abdullah Atli \\ Suleyman Demir \\ Mehmet Gunes \\ Mehmet Cemal Kaya \\ Mahmut Bulut \\ Aytekin Sir}

Department of Psychiatry, Faculty of Medicine, Dicle University, Diyarbakir, Turkey
Correspondence: Aslihan Okan Ibiloglu Department of Psychiatry, Faculty of Medicine, Dicle University, Sur, $2 \mid 280$ Diyarbakir, Turkey

Tel $+904 / 2248800$ I ext 4667

Fax +90 412 2488523

Email aslihan.ibiloglu@dicle.edu.tr
Background: Suicide is an important health problem in Turkey as it is in all regions of the world. Suicidal behavior has multiple causes, which are broadly divided into those related to proximal stressors and those due to predisposition. Suicide statistics may be associated with mental health disorders, which are among the foremost predictors of suicide attempts. More than $90 \%$ of patients who commit suicide have a diagnosable psychiatric disorder, usually a major depressive disorder. Other major risk factors for suicide attempts are history of suicide attempts in the family, stressful life events, sleep disturbances, poor income, unemployment, severity of symptoms of depression, and anxiety. Sleep is a complex phenomenon. Sleep disturbances can therefore be contributed to the emergence of suicidal behavior allowing for the possibility of predicting future suicides.

Methods: We evaluated 106 patients who were admitted after suicide attempts to the Department of Psychiatry at Dicle University Faculty of Medicine. The recruited subjects were assessed by Structured Clinical Interview for DSM-IV Axis I disorders, and the intensity of symptoms was evaluated using the Beck Anxiety Inventory, Hamilton Depression Rating Scale, and Pittsburgh Sleep Quality Index. The mean values of the subjects attempting multiple and single suicides were compared using appropriate inferential statistical tests.

Results: Most suicide attempts are believed to be preventable. Our results revealed that a great variety of risk factors are associated with an increased risk for multiple suicide attempts. Most of these attempts appeared to be spontaneous and impulsive rather than planned. In particular, this study highlights the importance of previous suicide attempts, history of suicide in the family, history of stressful life events in the previous 6 months, poor income, unemployment, sleep disturbances, severe hopelessness with depression, and coexisting symptoms of anxiety as risk factors.

Conclusion: The first step in prevention of suicides is doubtlessly strong and reliable communication, due to the fact that the majority of subjects who commit suicide have had contact with a health professional during the month before the suicide.

Keywords: suicide, suicide attempt, sociodemographics, mental health, comorbidity, sleep disturbances

\section{Background}

Suicide is an important health problem in Turkey, as it is in all regions of the world; in fact, in recent years, $75 \%$ of global suicides occurred in low- and middle-income countries. ${ }^{1,2}$ According to data from the Turkish Statistical Institute, the total number of suicide deaths in Turkey has gradually increased, especially during the past few years. ${ }^{3}$ Attempted suicide is defined as any potentially self-injurious action with a nonfatal outcome for which there is evidence, either explicit or implicit, that the individual intended to kill himself or herself. ${ }^{4}$

Suicide statistics may be associated with mental health. ${ }^{5}$ Prevalence studies show that between $4 \%$ and $12 \%$ of the general population have made at least one attempt 
and the repetition ratio (persons who attempt suicide again) is $50 \%{ }^{6}$ The overall suicide ratio was 3.94 per 100,000 in $1998 ;^{7}$ subsequently, this ratio increased to 4.02 per 100,000 , including women and men of all ages. ${ }^{8}$ According to the World Health Organization, worldwide suicide rates have increased by $60 \%$ in the past few years. ${ }^{9}$ Although some studies have found suicide rates to be higher globally in urban centers compared to that in rural areas due to crowding and social isolation, ${ }^{5,10}$ many reports have also claimed that the suicide rates in rural areas are threefold that in urban areas. ${ }^{11,12}$ Unfortunately, in Turkey as well as in some other countries, the only data available on suicide attempts are those obtained from hospital and police records, which are not maintained systematically.

It is known that stress or stressful life events (SLEs) may be among the foremost factors in predicting sleep quality, psychiatric disorders, and suicide attempts. SLEs may be minor hassles or serious life challenges. In addition, stressors of life can also be thoughts and memories of painful past events. ${ }^{13-15}$ The majority of suicidal people desperately want to live; they are just unable to see alternatives for solving their problems or SLEs. ${ }^{16,17}$ It should be noted that many individual risk factors (such as depression, family history of suicide, prior suicide attempt, as well as demographic and personality features) may coexist, and the number of attempts is increased with an increasing number of accompanying risk factors. ${ }^{16,18}$

Currently, one growing area of research includes the study of psychiatric disorders, sleep complaints, and suicide attempts. ${ }^{19,20}$ Sleep loss is associated with suicidal tendency, but the direction of causality is equivocal. ${ }^{10,21}$ A number of biological studies suggest that low serotonin (5-hydroxytryptamine) activity is associated with suicidal behavior, depressed mood, and poor sleep quality. ${ }^{22-24}$

In this study, we aimed to investigate the factors underlying single and multiple suicide attempts, hypothesizing that individuals with multiple suicide attempts would have higher rates of psychiatric disorders with sleep disturbances.

\section{Methods}

\section{Study design/participants}

This study used a cross-sectional design on patients who were admitted to the Department of Psychiatry of Dicle University Hospital, in Diyarbakir, a city in the Southeastern region of Turkey, after attempts to commit suicide within the previous 3 days.

Clinical assessments were conducted, face to face, by two experienced psychiatrists (AOI, AA), after the medical condition was stabilized. Each interview began with the explanation of the study objectives to all participants and that their information was to be used only for scientific purposes. Written and informed consent was obtained from all participants, and the study was approved by The Regional Committee for Research Ethics of Dicle University Faculty of Medicine and performed in accordance with the Helsinki Declaration of $2013 .^{25}$

A suicide attempt was defined by all participants as intent to end one's life. Each participant was encouraged to talk freely and in detail about their experiences and it was decided whether the suicide attempt had been planned or was the result of an impulsive act. Open-ended questions that were used to explore the issues surrounding the suicide attempts of the participants were included to let them give their view of what happened prior to and on the day of the incident. Individuals who were found to present with at least two lifetime suicide attempts were included in the multiple suicide attempters (MA) group.

SLEs include exposure to unusual, troublesome events, such as financial losses, suffering of the patient or other family members from a medical illness, problems with social or familial relations, marital conflicts, divorce, or domestic violence, which have the potential to change the patterns of life or stimulate many unpleasant feelings. SLEs in all six domains were common in the previous 6 months. These items were chosen as the SLEs to be asked to the participants. The study participants were asked if they had experienced any one of the SLEs during the previous 6 months in their life. Resulting answers were coded in a binary "yes" or "no" format.

Inclusion criteria included voluntary admission after having made a nonfatal suicide attempt, an ability to read and understand the consent form, and age between 18 years and 55 years. It is known that, in some cases, suicidal thinking may be linked to an underlying physical health problem (such as thyroid disease, diabetes mellitus, or Wilson's disease) or comorbidity of substance abuse and personality disorders with psychiatric disorders. Accordingly, the exclusion criteria were refusal to participate, the existence of any medical risk posed by psychiatric interview, the presence of severely disturbed behavior, or receipt of rapid tranquilization for such behavior on the day of sampling, inability to understand the study procedures, mental retardation and lack of capacity to give informed consent, a significant impairment in physical condition (such as trauma, dementia, or renal failure), history of a sleep disorder (eg, obstructive sleep apnea, narcolepsy), and a previous diagnosis of schizophrenia and/or active psychotic features. 


\section{Assessment procedure}

The interviews were administered in two parts. The first part included a core diagnostic assessment of Diagnostic and Statistical Manual of Mental Disorders, Fourth Edition (DSM-IV) criteria, ${ }^{26}$ along with sociodemographic information and questions on suicidal behaviors administered to all participants. In the second part, the diagnosis was reconfirmed at the time of evaluation by administering the Structured Clinical Interview for DSM-IV Axis I disorders (SCID-I). ${ }^{27}$ The symptom intensity was assessed using the Beck Anxiety Inventory (BAI), ${ }^{28,29}$ Hamilton Depression Rating Scale (HAMD), ${ }^{30,31}$ and subjective sleep quality was assessed using the Pittsburgh Sleep Quality Index (PSQI). ${ }^{32,33}$ Further details regarding the participants, such as premorbid personality and illness, were cross-checked with a close relative or a reliable informant.

First, 154 patients who agreed to participate were evaluated. Of those, 48 did not complete the baseline assessment because 22 had coexisting alcohol or substance abuse, 12 had personality disorders, three had a history of seizures or other neurologic disorders, and eleven had active medical disorders. Therefore, these 48 cases were excluded from the analyses. At the end, a total of 106 patients made up the study group. No patient refused participation.

\section{Materials}

\section{Sociodemographics}

A sociodemographic data questionnaire was used to determine age, marital status, educational level, employment status, socioeconomic status (current), household monthly income, and other features. This form was prepared by the experienced researchers, taking into account the sociocultural characteristics of the region.

\section{The Beck Anxiety Inventory}

The BAI was created by Beck et al ${ }^{28}$ based on the cognitive theory. It consists of 21 somatic and cognitive anxiety symptoms. Each symptom is ranked on a four-point scale ranging from 0 (not at all) to 3 (severe). The total score ranges from 0 to 63 . The cutoff point is accepted as $17 .{ }^{28}$ The validity and reliability of the Turkish version were also studied. ${ }^{29}$

\section{The Hamilton Depression Rating Scale}

The HAMD is a clinician-administered rating scale to assess symptom severity in depressive disorders. ${ }^{30}$ The validity and the reliability of Turkish HAMD scale scores were demonstrated. ${ }^{31}$

\section{The Pittsburgh Sleep Quality Index}

The PSQI is a 19-item self-report questionnaire that explores subjective sleep quality, evaluating seven components, such as subjective sleep quality, sleep disturbances, sleep latency, sleep duration, daytime dysfunction, habitual sleep efficiency, and use of sleep medications, over the past 30 days. The PSQI may be coalesced into one global score; a global PSQI score $>5$ is considered to be a sensitive and specific measure of poor sleep quality. ${ }^{33}$ Validity and reliability of the PSQI in the Turkish population were evaluated by Agargun et al. ${ }^{32}$

\section{Statistical analysis}

All statistical analyses were performed using the Statistical Package for the Social Sciences version 16 (SPSS). ${ }^{34}$ Descriptive statistics including means, standard deviations, frequencies, and percentages were used to summarize the demographic and clinical data. Inferential statistics in the form of Student's $t$-test and chi-square test were used to compare the MA group with the single suicide attempters (SA) group, as appropriate. Logistic regression analysis was conducted to identify the independent predictors of suicide attempt. The significance level was set at 0.05 in all analyses.

\section{Results}

The 106 patients who completed the clinical interview during the study period were included in the analysis. Of them, 56 were classified as MA, whereas the remaining 50 patients were classified as SA. The demographic characteristics of the patients with MA and SA are shown in Table 1.

Of the patients, $53.8 \%(n=57)$ were females and $46.2 \%$ $(n=49)$ were males. Mean age of the patients included in the study at the time of evaluation was $31.86 \pm 7.46$ years. The mean age of the female patients was $30.86 \pm 6.78$ years; whereas the mean age of the male patients was $33.02 \pm 8.1$ years. Our patients were predominantly middle-aged females. The participants tended to be from an impoverished area of a rural city: $91.5 \%$ reported poor socioeconomic conditions (namely, poor income), and the mean level of education was $9.53 \pm 3.65$ years. The MA and SA groups did not differ significantly in terms of $\operatorname{sex}\left(\chi^{2}=0.002, d f=1, P=0.93\right)$, marital status $\left(\chi^{2}=4.233, d f=2, P=0.248\right)$, habitus $\left(\chi^{2}=2.764, d f=2\right.$, $P=0.075)$, level of income $\left(\chi^{2}=1.654, d f=2, P=0.719\right)$, and permanent residence $\left(\chi^{2}=0.983, d f=2, P=0.612\right)$. However, we found that MA and SA significantly differed with regard to age $\left(\chi^{2}=10.127, d f=3, P=0.018\right)$, education $\left(\chi^{2}=7.401, d f=2\right.$, $P=0.025)$, and occupation $\left(\chi^{2}=11.806, d f=4, P=0.019\right)$. 
Table I Demographic features of participants

\begin{tabular}{|c|c|c|}
\hline & MA & SA \\
\hline & $n=56(52.8 \%)$ & $n=50(47.2 \%)$ \\
\hline \multicolumn{3}{|l|}{ Sex } \\
\hline Female & $30(53.6)$ & $27(54.0)$ \\
\hline Male & $26(46.4)$ & $23(46.0)$ \\
\hline \multicolumn{3}{|l|}{ Habitus } \\
\hline None & $12(2 \mid .4)$ & $18(36.0)$ \\
\hline Smoking & $33(58.9)$ & $24(48.0)$ \\
\hline Smoking and alcohol consumption & II (19.6) & $8(16.0)$ \\
\hline \multicolumn{3}{|c|}{ Marital status } \\
\hline Married & $29(51.8)$ & $16(32.0)$ \\
\hline Single & $15(26.8)$ & $19(38.0)$ \\
\hline Widowed/divorced & $12(2 \mid .4)$ & $15(30.0)$ \\
\hline \multicolumn{3}{|l|}{ Occupation } \\
\hline Housewife & $13(23.2)$ & $4(8.0)$ \\
\hline Elementary occupations & $16(28.6)$ & $24(48.0)$ \\
\hline Officer & $17(30.4)$ & $20(40.0)$ \\
\hline Unemployment & $3(5.4)$ & I (2.0) \\
\hline Agricultural workers & $7(12.5)$ & I (2.0) \\
\hline \multicolumn{3}{|l|}{ Work status } \\
\hline Working & $36(64.3)$ & $43(86.0)$ \\
\hline Not working & $20(35.7)$ & $7(\mid 4.0)$ \\
\hline
\end{tabular}

Abbreviations: MA, multiple suicide attempts; SA, single suicide attempt.
This was a first suicide attempt for $47.2 \%$ of these patients. The clinical and suicidal characteristics of both the groups are depicted in Table 2. Generally, mean age of the first suicide attempt was $25.45 \pm 7.77$ years. The peak incidence of suicide attempts for this study was between the ages of 26 years and 35 years (39.6\%). There was a statistically significant positive relationship between the MA and the age of onset of attempts $(r=+0.0614, P=0.00)$. This suggests that there was an increase in the number of suicide attempts at later ages.

It was noteworthy that $22.6 \%(\mathrm{n}=24)$ of these patients had seen a physician within the month prior to the suicide attempt, while $11.3 \%(n=12)$ had been seen by a psychiatrist. Thus, $34.0 \%(\mathrm{n}=36)$ had made contact with some health provider within the month prior to their suicide attempt. Twenty-four (22.6\%) of 36 patients (34.0\%) reported that they had not been asked by their health provider about their emotional state or if they were suicidal.

The mean age at onset of psychiatric disorders was 25.26 \pm 5.06 years. The most common psychiatric diagnosis

Table 2 Clinical and suicidal characteristics

\begin{tabular}{|c|c|c|}
\hline \multirow[t]{2}{*}{ Clinical features } & \multirow{2}{*}{$\frac{\text { MA, mean } \pm \text { SD }}{n=56(52.8 \%)}$} & \multirow{2}{*}{$\begin{array}{l}\text { SA, mean } \pm \text { SD } \\
n=50(47.2 \%)\end{array}$} \\
\hline & & \\
\hline Age (years) & $32.28 \pm 7.14$ & $31.38 \pm 7.85$ \\
\hline Education (years) & $8.68 \pm 3.54$ & $10.48 \pm 3.57$ \\
\hline Age of first suicide attempt & $20.96 \pm 4.11$ & $30.48 \pm 7.85$ \\
\hline Number of suicide attempts & $3.018 \pm 0.86$ & None \\
\hline Mean duration of mental illness (years) & $7.42 \pm 4.48$ & $5.3 \pm 4.06$ \\
\hline Sum of PSQI score & $|4.48 \pm 3.9|$ & $10.18 \pm 7.09$ \\
\hline Sum of HAMD score & $13.19 \pm 5.02$ & $11.96 \pm 6.703$ \\
\hline Sum of BAI score & $28.62 \pm 12.69$ & $25.84 \pm 13.89$ \\
\hline Suicide characteristics & MA, n (\%) & SA, n (\%) \\
\hline \multicolumn{3}{|l|}{ Method of the last suicide attempt } \\
\hline Prescription drugs & $42(75.0)$ & $45(90.0)$ \\
\hline Natural gas or liquefied petroleum gas etc & $4(7.1)$ & I $(2.0)$ \\
\hline Sharp instrument & $9(16.1)$ & $4(8.0)$ \\
\hline By burning & $\mathrm{I}(\mathrm{I} .8)$ & None \\
\hline \multicolumn{3}{|l|}{ Admission before the suicide? } \\
\hline Seen a physician & $10(17.9)$ & $14(28.0)$ \\
\hline Seen a psychiatrist & $5(8.9)$ & $7(14.0)$ \\
\hline None & $4 I(73.2)$ & $29(58.0)$ \\
\hline \multicolumn{3}{|l|}{ Stressful life events (past 6 months) } \\
\hline Yes & $54(96.4)$ & $43(86.0)$ \\
\hline No & $2(3.6)$ & $7(14.0)$ \\
\hline \multicolumn{3}{|l|}{ Family history } \\
\hline \multicolumn{3}{|l|}{ Suicide attempt } \\
\hline Yes & $37(67.3)$ & I8 (32.7) \\
\hline No & $19(37.3)$ & $32(62.7)$ \\
\hline \multicolumn{3}{|l|}{ Suicide-related death } \\
\hline Yes & $13(23.2)$ & I (2.0) \\
\hline No & $43(76.8)$ & $49(98.0)$ \\
\hline
\end{tabular}

Abbreviations: BAI, Beck Anxiety Inventory; HAMD, Hamilton Depression Rating Scale; MA, multiple suicide attempts; PSQI, Pittsburgh Sleep Quality Index; SA, single suicide attempt. 
was major depressive disorder (MDD) (35.8\%), followed by generalized anxiety disorder (GAD) (18.9\%), posttraumatic stress disorder (PTSD) (17.9\%), panic disorder (PD) (11.3\%), social phobia (SP) (9.4\%), and dysthymia (Dys) (6.6\%). As noted, among the current psychiatric diagnoses assigned by the clinicians was a significantly greater rate of MDD in the MA group compared to that in SA. Next in order were GAD and PTSD. On the other hand, the risk of MDD was highest for participants in the MA group (odds ratio $=1.64$, $95 \%$ confidence interval $=0.67-3.24, P=0.00)$.

At the time of admission, $42.5 \%(n=45)$ of patients were having current/ongoing psychiatric treatment. Only $57.5 \%$ $(\mathrm{n}=61)$ of suicidal patients had never received any psychiatric treatment. A total of $22.6 \%(n=24)$ patients had previously been psychiatric inpatients. Hopelessness, which is one of the depressive symptoms, was reported by $38.7 \%$. Additionally, insomnia was reported by $17.9 \%$, anhedonia by $13.2 \%$, and feelings of worthlessness and helplessness by $17.0 \%$ and $13.2 \%$, respectively. The scores of depression obtained using the HAMD were significantly worse in the MA group $(P=0.001)$. These data suggest that those in MA may be considerably depressed compared to those in the SA group. However, the scores of anxiety, measured using the BAI, were not worse than those in the MA group $(P>0.05)$.

Most of these attempts appeared to be more spontaneous and impulsive than planned. In our review of 106 suicide attempts, $86(81.1 \%)$ patients had no specific suicidal plan prior to their suicide attempt. Moreover, 77.4\% $(n=82)$ reported that they had only fleeting thoughts of suicide prior to their suicide attempt. In all, $22.6 \%$ of the patients $(n=24)$ reported that they had suicidal thoughts that were persistent prior to their attempted suicide. Only $18.9 \%$ left a suicide note. The majority of suicides in this study had occurred by the method of taking prescription drugs (82.1\%). It was observed that using a sharp instrument $(12.3 \%)$ and using natural gas/liquefied petroleum gas, etc (4.7\%) were the second and third most frequent methods of suicide, respectively.

SLEs during the previous 6 months were common in all five domains. The majority of these patients (42.5\%) experienced a current relationship conflict with their spouse or family. In terms of the losses experienced, $34.9 \%$ had significant financial losses. Furthermore, 13.2\% suffered from a medical illness. In $9.4 \%$ of patients, one of the family members suffered from a chronic deteriorating medical illness. Those in MA group recollected a greater number of SLEs as compared to those in the SA group $(P=0.03)$. The most common stressors in the MA group included spouse or family conflict, financial losses, and suffering from medical illness.
There was a positive family history for suicide in 55 of these patients and no family history of suicide in 51 cases. In cases wherein a family member had attempted suicide, it was a first-degree relative in $20(18.9 \%)$ cases, a seconddegree relative in $25(23.6 \%)$ of the cases, and it was some other distant relative in the remaining 10 (9.4\%) cases. Furthermore, there was a positive family history for suiciderelated death in $14(13.2 \%)$ of these patients and no family history of suicide-related death in $92(86.8 \%)$ cases. In this study, we identified that significant differences existed in terms of existence of family history of suicide attempts between the MA and SA groups $\left(\chi^{2}=24.30, P=0.001\right)$. Specifically, the MA group had significantly higher rates of history of suicide attempts among family members $(67.3 \%$ versus $32.7 \%$ ) and death by suicide among family members (23.2\% versus $2.0 \%$ ) than the SA group (Table 2 ).

The PSQI has seven component scores that measured various aspects of sleep. In all, 75.5\% $(n=80)$ of the study participants reported themselves as poor sleepers. Total PSQI scores were $>5$ points in $92.9 \%(n=52)$ of the MA and in $56.0 \%(n=28)$ of the $\mathrm{SA}$, indicating poor sleep quality. Sleep disturbances in suicide attempters according to PSQI are shown in Table 3.

In both MA and SA groups, elevated levels of anxiety were significantly correlated with poor sleep quality. The most common complaint in the MA and SA groups was difficulties in initiating sleep. Other complaints included difficulties in maintaining sleep (69\%), nightmares (66\%), and early morning awakening (58\%). Sleep disturbances were even more prevalent among the suicide attempters group, who went on to make multiple or single attempts $(65.0 \%$ and $35.0 \%$, respectively; $P=0.00)$. When the MA and SA groups were compared in terms of subjective sleep complaints, total PSQI scores were significantly higher in the

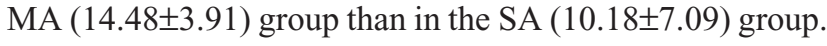
Linear regression analysis was performed to investigate the relationship between multiple attempts and the sum of scores for PSQI. There was a significant relationship between the multiple attempts and the sum of scores for PSQI ( $F=99.48$; $P=0.00)$.

\section{Discussion}

This study was conducted in Diyarbakir, which is an impoverished city in the southeast of Turkey, which has received a lot of migration. We know that rates of suicide also tend to vary a little when members from a culture migrate to another region, at least during the first years of settlement, as it was found in Turkey. ${ }^{16,35}$ Some patients will only attempt suicide, whereas other patients will make many attempts and will 
Table 3 Sleep disturbances in suicide attempters

\begin{tabular}{|c|c|c|c|c|}
\hline \multirow{2}{*}{$\begin{array}{l}\text { Sleep } \\
\text { disturbances }\end{array}$} & \multicolumn{2}{|l|}{ MA $(n=56)$} & \multicolumn{2}{|l|}{ SA $(n=50)$} \\
\hline & $\begin{array}{l}\text { Poor sleeper } \\
\text { (PSQI >5), n (\%) }\end{array}$ & $\begin{array}{l}\text { Good sleeper } \\
\text { (PSQI <5), n (\%) }\end{array}$ & $\begin{array}{l}\text { Poor sleeper } \\
(\text { PSQI >5), n (\%) }\end{array}$ & $\begin{array}{l}\text { Good sleeper } \\
\text { (PSQI <5), n (\%) }\end{array}$ \\
\hline \multicolumn{5}{|c|}{ Altered sleep quality } \\
\hline Fairly good & $28(53.8)$ & $4(100.0)$ & - & $21(95.5)$ \\
\hline Fairly bad & $24(46.2)$ & - & $19(67.9)$ & I (4.5) \\
\hline Very bad & - & - & $9(32.1)$ & - \\
\hline \multicolumn{5}{|c|}{ Prolonged sleep latency } \\
\hline$<30$ minutes & $25(48.1)$ & $3(75.0)$ & $7(25.0)$ & $16(72.7)$ \\
\hline$>30$ minutes & $27(51.9)$ & I (25.0) & $21(75.0)$ & $6(27.3)$ \\
\hline \multicolumn{5}{|c|}{ Decreased sleep duration } \\
\hline$<7$ hours & $52(100.0)$ & $4(100.0)$ & $23(82.1)$ & - \\
\hline$>8$ hours & - & - & $5(17.9)$ & $22(100.0)$ \\
\hline \multicolumn{5}{|c|}{ Habitual sleep efficiency } \\
\hline$<85 \%$ & $52(100.0)$ & $2(50.0)$ & $28(100.0)$ & $5(22.7)$ \\
\hline$>85 \%$ & - & $2(50.0)$ & - & $17(77.3)$ \\
\hline \multicolumn{5}{|c|}{ Use of sleeping medication } \\
\hline Yes & $33(63.5)$ & I (25.0) & $20(7 \mid .4)$ & $3(13.6)$ \\
\hline No & $19(36.5)$ & $3(75.0)$ & $8(28.6)$ & $19(86.4)$ \\
\hline \multicolumn{5}{|c|}{ Daytime dysfunction } \\
\hline Yes & $40(76.9)$ & $3(75.0)$ & $23(82.1)$ & $3(13.6)$ \\
\hline No & $12(23.1)$ & I (25.0) & $5(17.9)$ & $19(86.4)$ \\
\hline \multicolumn{5}{|c|}{ Rate of sleep quality } \\
\hline PSQI >5 & $52(92.9)$ & $4(7.1)$ & $28(56.0)$ & $22(44.0)$ \\
\hline
\end{tabular}

Abbreviations: MA, multiple suicide attempts; PSQI, Pittsburgh Sleep Quality Index; SA, single suicide attempt.

eventually die from suicide. ${ }^{36,37}$ Consistent with our results, approximately three females attempted suicide for every male who attempted suicide; however, repeat attempters were more likely to be of the male sex. ${ }^{12,38}$ The main economic activity in the region is farming. In this study, the majority of patients $(91.5 \%)$ were from the poor-income classes. As a result, low income and unemployment were risk factors for suicide, ${ }^{20,39}$ but this association might be biased because mental illnesses and psychosocial stressors contribute to both suicides and employment status. ${ }^{40,41}$ Although according to the literature, MA were more likely to be divorced/widowed ${ }^{42}$ and less educated than SA, ${ }^{18,43}$ the bulk of our patients who made multiple attempts were currently married (42.5\%). One study that is compatible with our study reported that as many as $67 \%$ of the persons who committed suicide were married. ${ }^{13}$

Suicide rates increase with age; however, the absolute numbers are highest among those $<45$ years of age. ${ }^{44}$ Similarly, the peak incidence for suicide attempts in this study occurred in patients between the ages of 26 years and 35 years $(39.6 \%)$, and the rates of suicide attempts more likely differ dramatically by age. Nevertheless, it is obvious that no pathognomonic risk factors exist. In our study, the majority of our participants were smokers $(71.7 \%)$. Several studies have revealed the positive relationship between smoking and suicides. This relationship seems to be dose related. ${ }^{45-47}$ Of course, a variety of factors are associated with an increased risk for suicide attempts, including presence of psychiatric disorders, SLEs, sleep disturbances, history of previous suicide attempts, or history of suicide attempts in the family. ${ }^{1,13,16}$

Of the 106 participants, 56 were classified as MA and 50 were SA. Generally, women tend to choose less lethal suicide methods than men do (eg, overdose versus firearms or hanging) ${ }^{1,45}$ In this study, the most frequent method of committing suicide was the method of taking prescription drugs $(82.1 \%)$. It was observed that using a sharp instrument $(12.3 \%)$ and using natural gas/liquefied petroleum gas, etc $(4.7 \%)$ are the second and third methods of suicide, respectively. There was a significant relationship between multiple attempts and suicide methods. Similarly, in one study, ${ }^{48}$ attempted suicide by poisoning was the most common method, used by $83.8 \%$ of attempters, which was linked to later-completed suicides. Studies have shown that many suicide attempts are unplanned and occur during an acute period of ambivalence, as seen in our study. ${ }^{49}$ Most of the suicide attempts appeared to be more spontaneous (81.1\%) than planned, as well as being the first suicide attempt for $47.2 \%$ of our participants. Only $18.9 \%$ of patients left a suicide note or message. It is known that, rates of suicide 
attempts and methods utilized in one culture may be unusual in another setting. 1,50

It should be noted that SLEs often occur before a person attempts or commits suicide. As our study suggests, SLEs may be related to the growing number of suicide attempts as well as many processes that can be recognized from general theories on suicidal attempts. The majority of our patients $(42.5 \%)$ were experiencing a current relationship conflict with their spouse or family. This was most significant to the females when compared to the male population. Financial problems were the second most frequently identified stressor in this population. As in many studies supporting our results, there was a statistically significant relationship between multiple attempts and recent SLEs. ${ }^{6,14,15}$ One psychological autopsy study found that most suicide victims (70\%) reported multiple SLEs as well as a high rate of life events during the week before the suicide attempt. Furthermore, psychiatric diagnoses were less important, relative to SLEs, in predicting the suicide attempters' group. ${ }^{51}$

Family history of attempted suicide is among the many predictors that can contribute to a person's vulnerability. ${ }^{47}$ Our study showed that MA patients were approximately twice as likely as SA members to report suicide attempts among family members (67.3\% versus $32.7 \%)$. For some of our patients, suicides among close relatives seem to have influenced their actions. ${ }^{8}$ This condition may have been the effect of suicide contagion (imitative behavior). ${ }^{52}$ Similarly, we identified that a significant positive relationship was found between the family history of suicide and the multiple attempts reported. These findings are quite similar to other reports in the literature. . $^{14,43,53}$

A previous suicide attempt is the strongest predictor of a future completed suicide. ${ }^{39}$ About $20 \%$ of people who die by suicide have made a prior suicide attempt, and many clinical studies have confirmed that such prior attempts increase a person's risk for subsequent suicide death. ${ }^{54}$ Unfortunately, as in our study, most people said that they had not been asked about their state of mind or suicidal potential during their admission..$^{55,56}$ Therefore, past history of mental illness should be viewed as a marker that alerts all clinicians to an increase in suicide risk. ${ }^{56,57}$

In this study, the mean age at onset of psychiatric disorders was $25.26 \pm 5.06$ years. Participants in our study had only one psychiatric diagnosis according to the SCID-I. The most common psychiatric diagnosis was MDD (35.8\%), followed by GAD (18.9\%), PTSD (17.9\%), PD (11.3\%), SP (9.4\%), and Dys $(6.6 \%)$, respectively. Similar to many studies in the literature, ${ }^{53,58,59}>90 \%$ of suicide attempters had MDD
$(56 \%-87 \%)$. These findings reflect the consistency of the variables that were referred to in the previous literature.

Disturbed sleep is defined as mainly a matter of difficulties in initiating or maintaining sleep. ${ }^{60}$ Suicide attempters have longer sleep latency, fewer late-night delta counts, and longer duration of REM. ${ }^{19}$ Recently, sleep alterations have been determined as potential risk factors for suicidal attempts. ${ }^{5,60,61}$ In other words, sleep and its disorders are particularly relevant to psychiatric practice. ${ }^{20,21}$ Similarly, this study points out the correlation between suicide attempts and sleep disturbances: $75.5 \%$ of our participants reported themselves as poor sleepers. Sleep disturbances were even more prevalent among the suicide attempters who went on to make multiple attempts (92.9\%) compared to those who made a single attempt (56.0\%), and the total PSQI scores were significantly higher in the MA group than in the SA group. The most common complaint that MA and SA patients had was difficulty in initiating sleep. Other complaints included difficulties in maintaining sleep (69\%), occurrence of nightmares (66\%), and early morning awakening (58\%). Recently, a few studies have assessed the correlations between alterations in circadian/seasonal rhythms and vegetative functions and suicidality, but most recent articles in this field should be better analyzed and discussed. ${ }^{20,43,61}$ Clinical studies have shown that suicidal ideation during depression is frequent in patients with insomnia compared to depressed patients without insomnia. ${ }^{57}$ A critique of the hypothesis that increasing sleep may reduce suicide rates was recently published. ${ }^{24,56}$ This study provides a good description of the conditions that may predispose one to suicide attempts, similar to many studies. ${ }^{20,21,56,61}$

Anxiety has been suggested to increase the risk of suicide even when any specific anxiety disorder is not present. The BAI scores were significantly higher for MA than for SA, and our data suggest that MA patients may be considerably more anxious than SA patients. Patients who are greatly upset by major stressors may have anxiety symptoms, with disturbed sleep quality as part of an acute stress response. Data on lifetime rates of suicide among patients with anxiety disorders are associated with a six- to tenfold increase in suicide risk, but again, comorbid diagnoses may play a role in mediating this effect. ${ }^{2,53,58}$

In our study, the risk of multiple attempts was highest for participants with MDD. Moreover, the HAMD scores were significantly higher for MA than for SA; our data suggest that MA may be considerably depressed and feeling hopeless than the SA group. These results are consistent with previous studies of the effects of hopelessness on suicide risk. ${ }^{28,59}$ 
Previous studies report that suicide and suicide attempts in patients with depression are associated with inadequate communication or treatment. ${ }^{2,5,6}$ In our population, only $42.5 \%$ of patients were under psychiatric treatment at the moment of admission. Further, a total of $22.6 \%$ had previously been undergoing psychiatric treatment. Regarding risk factors for attempting suicide, compared to first-time attempters, repeat attempters had more previous psychiatric treatment. ${ }^{57}$ As mentioned above, the group of people with multiple attempts has been identified as having greater severity of depressive and anxiety symptoms, greater comorbidity with sleep disturbances, and often a history of family suicide attempts. ${ }^{18,20,21,56}$

Depression showed the strongest relationship with suicide, and poor sleep quality increased the risk for suicide by $34 \% .{ }^{35}$ Similarly, one study in Turkey ${ }^{19}$ demonstrated a similar link between suicidality, depression, and sleep complaints. So much so, depression, suicide, and sleep complaints may share the same neurobiological mechanism. ${ }^{54,57}$

Any sudden or dramatic change affecting a person's performance, attendance, or behavior should be taken seriously. During the development of the suicidal process, mutual communication between suicidal young people and those around them is crucially important. Patients in whom symptoms of depression and anxiety are suspected should always be screened for suicidality by asking direct questions about suicide plans and the means available to carry out such plans. It should be noted that these factors help to identify persons at risk of mental and social stress who might have thoughts of suicide that ultimately lead to suicidal behavior.

Our study has some strengths and also methodological limitations related to logistic issues. First, the cross-sectional design of this study may not allow for determination of causality. Second, the suicide attempters in the study were not controlled with a healthy group. Third, sleep quality was assessed only by self-reports, and there were no other confirming sources for this information, such as from polysomnographic examination.

\section{Conclusion}

In conclusion, risk factors in this study found to be the most strongly associated with MA were prior history of suicide attempts of the patients and their family, SLEs, poor income, poor education, symptoms of depression, and anxiety or poor sleep. Finally, with these findings in mind, variations in suicide rates with any demographic and cultural factors may reflect differing rates of psychiatric disorders. Of note, future research is needed to examine this potentially important implication. Future research using more comprehensive, dimensional measures of co-occurring conditions is needed.

\section{Author contributions}

All authors (AOI, AA, SD, MB, MCK, MG, and AS) were equally involved in study design, data analysis, literature search, and critical revision. Acquisition of data, clinical assessments, and writing of this paper were conducted by AOI and AA. All authors contributed toward data analysis, drafting and critically revising the paper and agree to be accountable for all aspects of the work.

\section{Disclosure}

The authors report no conflicts of interest in this work.

\section{References}

1. Persson G, Danielsson M, Rosén M, et al. Health in Sweden: the National Public Health Report 2005. Scand J Public Health Suppl. 2006; 67:3-10.

2. Allgulander C. Suicide and mortality patterns in anxiety neurosis and depressive neurosis. Arch Gen Psychiatry. 1994;51:708-712.

3. Turkish Statistical Institute (TSI). Suicide Attempt Statistics TR31 Izmir 2013. Institute of Statistics. Ankara: Turkish Statistical Institute (TSI); 2013:14-17. Publication number: 4179.

4. American Psychiatric Association. Practice guidelines for the assessment and treatment of patients with suicidal behaviors. Am J Psychiatry. 2003; 160:1-59.

5. Hall RC, Platt DE. Suicide risk assessment: a review of risk factors for suicide in 100 patients who made severe suicide attempts. Evaluation of suicide risk in a time of managed care. Psychosomatics. 1999;40:18-27.

6. Indrayan A, Wysocki MJ, Kumar R, Chawla A, Singh N. Estimates of the years of life lost due to the top nine causes of death in rural areas of major states in India in 1995. Natl Med J India. 2002;15:1.

7. Canetto S, Sakinofsky I. The gender paradox in suicide. Suicide Life Threat Behav. 1998;28(1):1-23.

8. Gibb S, Beautrais A. Epidemiology of attempted suicide in Canterbury province, New Zealand (1993-2002). N Z Med J. 2004;117(1205): $1-9$.

9. World Health Organization. Suicide Rates Per 100,000 by Country, Year and Sex (Table). Geneva: World Health Organization; 2011.

10. Bernert RA, Joiner TE, Cukrowicz KC. Suicidality and sleep disturbances. Sleep. 2005;28(9):1135-1141.

11. Cao W, Wu T, An T, An T, Li L. Study on the mortality of injury in Chinese population in urban and rural areas from 1990 to 1997. Zhonghua Liu Xing Bing Xue Za Zhi. 2000;21:327-329.

12. Hawton $\mathrm{K}$, Van Heeringen $\mathrm{C}$, editors. International Handbook of Suicide and Attempted Suicide. Chichester: John Wiley and Sons; 2000.

13. Phillips MR, Yang G, Zhang Y, et al. Risk factors for suicide in China: a national case-control psychological autopsy study. Lancet. 2002; 360:1728-1736.

14. Pompili M, Innamorati M, Szanto K, et al. Life events as precipitants of suicide attempts among first-time suicide attempters, repeaters, and non-attempters. Psychiatry Res. 2011;186(2-3):300-305.

15. Pompili M, Innamorati M, Forte A, et al. Insomnia as a predictor of high-lethality suicide attempts. Int J Clin Pract. 2013;67(12): 1311-1316. 
16. Luoma JB, Martin CE, Pearson JL. Contact with mental health and primary care providers before suicide: a review of the evidence. Am J Psychiatry. 2002;159(6):909-916.

17. Smith K, Crawford S. Suicidal behavior among "normal" high school students. Suicide Life Threat Behav. 1986;16:313-325.

18. Goldsmith SK, Pellmar TC, Kleinman AM, Kleinman AM, Bunney WE, editors. Reducing Suicide: A National Imperative. Washington, DC: Institute of Medicine, The National Academies Press; 2002.

19. Agargun MY, Kara H, Solmaz M. Sleep disturbances and suicidal behavior in patients with major depression. J Clin Psychiatry. 1997;58 249-251.

20. Selvi Y, Aydin A, Boysan M, Atli A, Agargun MY, Besiroglu L. Associations between chronotype, sleep quality, suicidality, and depressive symptoms in patients with major depression and healthy controls. Chronobiol Int. 2010;27(9-10):1813-1828.

21. Agargun MY, Besiroglu L. Sleep and suicidality: do sleep disturbances predict suicide risk? Sleep. 2005;28:1039-1040.

22. Arango V, Huang YY, Underwood MD, Mann JJ. Genetics of the serotonergic system in suicidal behavior. J Psychiatr Res. 2003;37: 375-386.

23. Ursin R. Serotonin and sleep. Sleep Med Rev. 2002;6:57-69.

24. Fawcett J, Scheftner WA, Fogg L, et al. Time-related predictors of suicide in major affective disorder. Am J Psychiatry. 1990;147(9): 1189-1194.

25. Declaration of Helsinki: ethical principles for medical research involving human subjects. World Medical Association. JAMA. 2013; 310(20):2191-2194.

26. American Psychiatric Association. Diagnostic and Statistical Manual of Mental Disorders, Text Revision. 4th ed. Washington, DC: American Psychiatric Association; 2000.

27. First MB, Spitzer RL, Gibbon M, Williams JBW. Structured Clinical Interview for DSM-IV Axis I Disorders, Clinician Version (SCID-CV). Washington, DC: American Psychiatric Press, Inc; 1996.

28. Beck AT, Epstein N, Brown G, Steer RA. An inventory for measuring clinical anxiety: psychometric properties. J Consult Clin Psychol. 1988; 56:893-897.

29. Ulusoy M, Şahin N, Erkmen H. Turkish version of the Beck Anxiety Inventory. J Cogn Psychoter. 1998;12:163-172.

30. Hamilton M. A rating scale for depression. J Neurol Neurosurg Psychiatry. 1960;23:56-62.

31. Akdemir A, Turkcapar MH, Orsel SD, Demirergi N, Dag I, Ozbay MH. Reliability and validity of the Turkish version of the Hamilton Depression Rating Scale. Compr Psychiatry. 2001;42:1615.

32. Agargun MY, Kara H, Anlar O. Validity and reliability of the Pittsburgh sleep quality index in Turkish sample. TurkJ Psychiatry. 1996; 7:107-115.

33. Buysse DJ, Reynolds CF, Monk TH, Berman SR, Kupfer DJ. The Pittsburgh sleep quality index: a new instrument for psychiatric practice and research. Psychiatr Res. 1989;2:193-213.

34. SPSS Inc. SPSS for Windows, Version 16.0. Chicago: SPSS Inc; 2007.

35. Turvey CL, Conwell Y, Jones M, et al. Risk factors for late-life suicide: a prospective, community-based study. Am J Geriatr Psychiatry. 2002;10(4):398-406

36. Rihmer A, Rihmer Z, Jekkel E, Kárteszi M, Csiszér N, Farkas A. Psychiatric characteristics of 100 nonviolent suicide attempters in Hungary. Int J Psychiatry Clin Pract. 2006;10(1):69-72.

37. Schmidtke A, Bille-Brahe U, Deleo D, et al. Attempted suicide in Europe: rates, trends and sociodemographic characteristics of suicide attempters during the period 1989-1992. Results of the WHO/EURO Multicentre Study on Parasuicide. Acta Psychiatr Scand. 1996;93(5): 327-338.

38. Raja M, Azzoni A. Suicide attempts: differences between unipolar and bipolar patients and among groups with different lethality risk. $J$ Affect Disord. 2004;82:437-442.
39. Beautrais AL, Joyce PR, Mulder RT. Youth suicide attempts: a social and demographic profile. Aust N Z J Psychiatry. 1998;32:349-357.

40. Agerbo E. High income, employment, postgraduate education, and marriage: a suicidal cocktail among psychiatric patients. Arch Gen Psychiatry. 2007;64:1377-1384.

41. Cullberg J, Wasserman D, Stefansson CG. Who commits suicide after a suicide attempt? An 8 to 10 year follow up in a suburban catchment area. Acta Psychiatr Scand. 1988;77:598-603.

42. Yip PS, Thorburn J. Marital status and the risk of suicide: experience from England and Wales, 1982-1996. Psychol Rep. 2004;94:401-407.

43. Goldstein TR, Bridge JA, Brent DA. Sleep disturbance preceding completed suicide in adolescents. J Consult Clin Psychol. 2008;76: 84-91.

44. De Silva D, Jayasinghe S. Suicide in Sri Lanka. In: Vijayakumar L, editor. Suicide in Sri Lanka. Suicide Prevention-Meeting the Challenge Together. Hyderabad: Orient Longman; 2003:178-190.

45. Haukka J, Suominen K, Partonen T, Lonnqvist J. Determinants and outcomes of serious attempted suicide: a nationwide study in Finland, 1996-2003. Am J Epidemiol. 2008;167:1155-1163.

46. Hughes JR. Smoking and suicide: a brief overview. Drug Alcohol Depend. 2008;98:169-178.

47. Mann JJ, Brent DA, Arango V. The neurobiology and genetics of suicide and attempted suicide: a focus on the serotonergic system. Neuropsychopharmacology. 2001;24:467-477.

48. Runeson B, Tidemalm D, Dahlin M, Lichtenstein P, Långström N. Method of attempted suicide as predictor of subsequent successful suicide: national long term cohort study. BMJ. 2010;13(341):c3222.

49. Bohanna I, Wang X. Media guidelines for the responsible reporting of suicide: a review of effectiveness. Crisis. 2012;33(4):190-198.

50. Kessing LV, Agerbo E, Mortensen PB. Does the impact of major stressful life events on the risk of developing depression change throughout life? Psychol Med. 2003;33(7):1177-1184.

51. Heikkinen ME, Henriksson MM, Isometsä ET, Marttunen MJ, Aro HM, Lönnqvist JK. Recent life events and suicide in personality disorders J Nerv Ment Dis. 1997;185(6):373-381.

52. Durkheim E. Suicide: A Study in Sociology by Emile Durkheim. New York: Free Press; 1966:254-257.

53. Beautrais A, Joyce P, Mulder R, Fergusson DM, Deavoll BJ, Nightingale SK. Prevalence and comorbidity of mental disorders in persons making serious suicide attempts: a case-control study. Am J Psychiatry. 1996;153:1009-1014.

54. Tidemalm D, Langstroem N, Lichtenstein P, Runeson B. Risk of suicide after suicide attempt according to coexisting psychiatric disorder: Swedish cohort study with long term follow-up. BMJ. 2008; 337(7682):a2205.

55. Caldera T, Herrera A, Renberg ES, Kullgren G. Parasuicide in a low-income country: results from three year hospital surveillance in Nicaragua. Scand J Public Health. 2004;32(5):349-355.

56. Simon RI. Chapter 43: suicide. In: Hales RE, Yudofsky SC, Gabbard GO, editors. The American Psychiatric Publishing Textbook of Psychiatry. 5th ed. Arlington, VA: American Psychiatric Publishing, Inc; 2008:1-32.

57. Chellappa SL, Araujo JF. Sleep disorders and suicidal ideation in patients with depressive disorder. Psychiatry Res. 2007;153:131-136.

58. Beautrais AL. Suicides and serious suicide attempts: two populations or one? Psychol Med. 2001;31:837-845.

59. Barraclough B, Bunch J, Nelson B, Sainsbury P. A hundred cases of suicide: clinical aspects. Br J Psychiatry. 1974;125:355-373.

60. Thorpy MJ. Classification of sleep disorders. Neurotherapeutics. 2012;9(4):687-701.

61. Dell'Osso L, Massimetti G, Conversano C, et al. Alterations in circadian/seasonal rhythms and vegetative functions are related to suicidality in DSM-5 PTSD. BMC Psychiatry. 2014;14:352. 


\section{Publish your work in this journal}

Neuropsychiatric Disease and Treatment is an international, peerreviewed journal of clinical therapeutics and pharmacology focusing on concise rapid reporting of clinical or pre-clinical studies on a range of neuropsychiatric and neurological disorders. This journal is indexed on PubMed Central, the 'PsycINFO' database and CAS,

and is the official journal of The International Neuropsychiatric Association (INA). The manuscript management system is completely online and includes a very quick and fair peer-review system, which is all easy to use. Visit http://www.dovepress.com/testimonials.php to read real quotes from published authors.

Submit your manuscript here: http://www.dovepress.com/neuropsychiatric-disease-and-treatment-journal 